\title{
Influence of cetane-detergent additives into diesel fuel with RME content increased to $10 \%$ on the parameters of indicator diagrams and rate of heat release in a diesel engine
}

\begin{abstract}
This publication is the next part of the article "The influence of cetane-detergent additives in diesel fuel increased to $10 \%$ of RME content on energy parameters and exhaust gas composition of a diesel engine". The cause-effect analysis of the phenomena related to the impact of 3 additive packages used in diesel oil with RME content increased to 10\% (compare to standard diesel fuel with $7 \%$ of $R M E$ ) was described. The basis for the analysis of the impact of the tested fuels on energy parameters and composition of exhaust gases were the parameters of indicator diagrams and heat release parameters. It was found that the first set of additives affects the delay of auto-ignition of fuel and kinetic fuel combustion speed only at low engine loads. In this range of engine operation the NOx concentration in the exhaust gas is low and besides there is a large of EGR. The second additive package was operated at high engine loads but its impact on the lower self-ignition delay was quantitatively small. Therefore, in the third packet of additives, the amount of additives used in the second packet was doubled. Then a satisfactory shortening of the self-ignition delay and reduction of the max rate of kinematic heat release was achieved as a reason of a reduction of $\mathrm{NO}_{x}$ concentration in the exhaust up to $8 \%$ (compared to the reference fuel).
\end{abstract}

Key words: cetane-detergent additives, RME, indicator diagram, heat release, diesel engine

\section{Introduction}

The paper is the second part of the article The influence of cetane-detergent additives in diesel fuel increased to $10 \%$ of RME content on energy parameters and exhaust gas composition of a diesel engine and is a cause-effect analysis of the phenomena related to the impact of 3 additive packages used in diesel oil with RME content increased to $10 \%$.

In the studies described in the first article, it was found that the first fuel additive package reduces the $\mathrm{NO}_{\mathrm{x}}$ concentration in a beneficial, though the insignificant way in the exhaust gases only at low engine loads. The second additive package quantitatively influenced the reduction of the $\mathrm{NO}_{\mathrm{x}}$ concentration in the engine exhaust in a similar way as the first additive. However, the effect of this additive was the more effective (from the point of view of reducing the $\mathrm{NO}_{\mathrm{x}}$ concentration) the higher the engine load. Due to the fact that the second additive package has been practically too small, it was decided to increase the amount of cetane additive in package 3 by a factor of 2 .

The article analyzes the correlation between the number and proportions of additives used in packages 1,2 and 3, and the parameters of indicator diagrams, as well as parameters of heat release graphs (including the maximum rate of kinetic and diffusion heat release), $\mathrm{NO}_{\mathrm{x}}$ concentration and smoke opacity. This operation allowed both the determination of the right direction of quantitative and qualitative changes in relation to the value of engine energy parameters and the composition of the exhaust for the engine fuelled by tested additive packages.

\section{Characteristics of tested fuels and research methodology}

Three Innocet $\left.{ }^{(}\right)$detergent-dispersing packages (A, B, and C) were used. The B10 diesel fuel (10\% (by vol.) of RME), whose physico-chemical characteristics are shown in Table 1, was enhanced with the $\mathrm{A}, \mathrm{B}$, and $\mathrm{C}$ Innocet ${ }^{\circledR}$ packages in the quantity of $1,500 \mathrm{mg} / \mathrm{kg}$. Such enhanced
B10 diesel fuel had cetane number equal to 58 . The Innocet $^{(B} \mathrm{A}, \mathrm{B}$, and $\mathrm{C}$ packages contained $50 \mathrm{mg} / \mathrm{kg}$ of a commercial detergent-dispersing additive and differed by the level of dosing of the stabilizers taking synergistic part in creation of free radicals in the area of low-temperature and indirect oxidation of the B10 diesel fuel. In this manner, 4 fuels were created, which then underwent engine tests:

- TM/134/18 - comparative fuel B7 (7\% (V/V) RME)

- TM/135/18 - B10 fuel with the Innocet ${ }^{\circledR}$ A package

- TM/136/18 - B10 fuel with the Innocet ${ }^{\circledR}$ B package

TM/154/18 - B10 fuel with the Innocet ${ }^{\circledR} \mathrm{C}$ package

The engine tests of the fuels in question were performed at the Internal-Combustion Engines Laboratory of the Institute of Motor Vehicles and Internal-Combustion Engines of the Cracow University of Technology.

Tests for each of the tested fuels were carried out using a 4-cylinder diesel engine, type 1.9 TDI (AJM version), made by VW, whose technical characteristics are shown in Table 2 .

In order to measure and analyze the parameters of the engine fuelled sequentially by tested fuels was used part of the measuring systems, which are equipped laboratory of Cracow University of Technology. The study was carried out using the popular VW 1.9 TDI engine in the AJM version (with unit injectors), popular in Europe, in passenger cars and light commercial vehicles. This article describes the influence of engine load (at max torque speed 2000 $\mathrm{rpm}$ ) on the basic engine parameters and exhaust composition. In the study were used Schenk engine dynamometer, AVL Fuel Balance (for measure of fuel consumption) and AVL Bench Emission System CEB II for measuring the concentration of gaseous components. In addition, the air temperature collected by the engine, the air temperature behind the turbocharger, behind the inter-cooler and into the intake manifold (behind the EGR valve) were measured. The exhaust gas temperature was measured before and after 
the turbocharger. For comprehensive analysis, the impact of the engine load on the boost pressure and the start of fuel injection were measured. In the second part of the article, the AVL Indimeter 617D was also used to determine and analyze the fast-changing pressure in the engine cylinder (as a function of the engine crankshaft rotation angle) and to calculate the rate of heat release.

\section{Delay of self-ignition}

The process of delay of chemical self-ignition continues to be the object of fundamental research consisting in modelling of the kinetics of advanced chemical reactions of oxidation of hydrocarbons. The process of oxidation of hydrocarbon fuels covers hundreds of grades of hydrocarbon compounds participating in thousands of chemical reactions which makes the entire process of low-temperature, transitional, and high-temperature oxidation very complex.

The chemistry and the delay time of self-ignition depend on the molecular structure of the diesel fuel and on the kinetics of the elementary reactions of low-temperature oxidation of hydrocarbons.

The process of self-ignition of diesel fuel is initiated by a start of reactions that generate free radicals produced from stable hydrocarbon compounds. The progress of branched chain reactions increases the number of free radicals involved in the self-ignition.

The chain reaction theory was developed and published by Nikolay Semyonov for which, together with Cyril Hinshelwood, he won the Noble Prize in Chemistry in 1956 [2].

Curran et al. presented [3] ten main categories of reactions involved in the process of chemical self-ignition:

I. Unimolecular decomposition (molecular elimination reaction);

II. Hydrogen atom transfer;

III. Oxygen addition reactions;

IV. Other addition of $\mathrm{H}^{\bullet},{ }^{\circ} \mathrm{OH}, \mathrm{HOO}^{\bullet}$ radicals and radical species to olefins;

V. Recombination reactions;

VI. $\beta$-decomposition;

VII. Isomerization reactions;

VIII. Creation of double bonds by elimination of two substituents in a one-stage reaction mechanism;

IX. Free-radical cyclization;

X. Reaction of disproportioning of two radicals.

The mechanism of low-temperature oxidation of hydrocarbons and of the self-ignition chemistry is also presented in the publication [4].

Self-ignition of diesel fuel takes place when the energy released by free-radical chain reactions results in an exponential increase of the temperature of the load in the engine cylinder, which of course is associated with a pressure surge in the cylinder. In the presented laboratory engine tests, this is how the start of self-ignition of the fuel was determined. Self-ignition delay, $t_{s}$, is defined in the publication as the angle of rotation of the engine crankshaft (determined with the accuracy of $0.1 \mathrm{deg}$ ) between the start of fuel injection (at a constant rotational speed and load on the engine - the same for all fuels) and the start of self-ignition of the fuel (determined based on the changes of the $\mathrm{dp} / \mathrm{d} \alpha$ in the engine cylinder). Such self-ignition delay $\left(t_{s}\right)$ is only a part of low-temperature oxidation of hydrocarbons and of the chemical part of self-ignition; however, the error made in the assumption is the same for all the tested fuels. This enables an analysis of cause and effect phenomena associated with use of the reference fuel and the fuels containing cetane-detergent additives.

\section{Experimental}

\subsection{Parameters of indicator diagrams}

Because the impact of engine load on most of the analyzed parameters is much higher than the impact of the tested fuel additives, a linear load characteristics analysis of the parameters of the indicator diagrams and the heat release speed is very difficult. Therefore, in order to perform a more accurate analysis, bar graphs were prepared, based on cross-sections of load characteristics, of all parameters for low, medium, and high load of the engine $(50 \mathrm{Nm}, 150$ $\mathrm{Nm}$, and $250 \mathrm{Nm}$ ). As a result, at changed value ranges (different for different engine loads) of specific parameters, it was easier to analyze the impact of the tested fuels on the analyzed parameters.

Historically, the oldest method of cause and effect analysis of fast-changing processes inside the cylinder of a combustion engine is its indication. Measurement of the pressure of the working medium in the engine cylinder as a function of the angle of rotation of the crankshaft continues to be used in order to analyze the processes taking place in the cylinder.

The measured indicator diagrams for the four fuels that were used and the seven engine loads (at a constant rotational speed that is characteristic for the maximum torque of the engine $n=2000 \mathrm{rpm}$ ) were used to determine a number of parameters that facilitated an analysis of the impact of fuel additives on the energy parameters and the composition of the exhaust gas. Those parameters include:

- start of fuel injection $\alpha_{\mathrm{pw}}$,

- start of fuel self-ignition $\alpha_{\mathrm{psp}}$,

- fuel self-ignition delay $\tau_{\mathrm{sp}}$,

- maximum rate of increase of combustion pressure $(\mathrm{dp} / \mathrm{d} \alpha)_{\max }$,

- maximum combustion pressure $\mathrm{p}_{\mathrm{s} \cdot \max }$,

- angle at which the combustion pressure is the highest $\alpha_{\text {ps.max }}$.

Moreover, the values of the pressure in the cylinder as a function of the crankshaft rotation angle (for the four fuels) were used to calculate the heat release speed in the engine cylinder, which is described in the next subchapter.

In order to determine the start of fuel injection $\left(\alpha_{\mathrm{pw}}\right)$, a VCDS computer diagnoscope, intended only for controllers used in VW engines, was used. A device of this type identifies the start of fuel injection $\left(\alpha_{\mathrm{pw}}\right)$ as a sudden increase of the value of the current controlling the opening of the fuel injector pumps. This is not the real start of fuel injection, because the needle of the injector pump is lifted 150-200 $\mu$ s after the start of the increase of the current impulse. However, even the start of the lifting of the injector (injector pump) needle does not necessarily take place exactly at the same time as the start of fuel injection. One can imagine a situation where the actual injection starts (the fuel flows through the outlet openings in the nozzle) when 
$10 \%$ of the maximum lift of the needle for diesel oil is achieved. However, for example in the case of a raw plant oil, whose viscosity is 18 times higher than the viscosity of diesel fuel, at the same lift of the injector needle there will be no fuel injection. Moreover, the real start of fuel injection may or may not take place (at the same lift of the injector needle) depending on the difference between the fuel pressure and the back pressure (the pressure in the engine cylinder). Having the above phenomena in mind, in the tests it was assumed that the fuel injection start $\left(\alpha_{\mathrm{pw}}\right)$ is equivalent to the start of the increase of the current control signal that opens the injector pump (the same viscosity of the tested fuels - the same error of determination of the $\alpha_{\mathrm{pw}}$ for all the fuels). As shown in Fig. 1, the start of fuel injection $\left(\alpha_{\mathrm{pw}}\right)$ determined in the same way for all the tested fuels is the same (within the measurement accuracy limits).

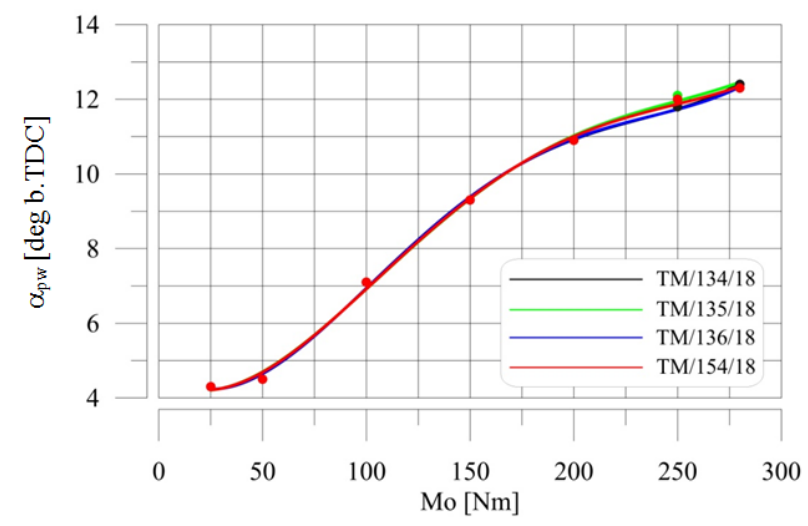

Fig. 1. Impact of the engine load on the start of fuel injection $\left(\alpha_{\mathrm{pw}}\right)$ for the 4 tested fuels

Of course, as the engine load increases, the optimum fuel injection start is earlier, which is ensured by the engine controller, in the same way for all the fuels.

As mentioned in chapter 3, the start of fuel self-ignition $\left(\alpha_{\mathrm{psp}}\right)$ in the engine cylinder was determined as the moment (angle of rotation of the crankshaft) when there is a pressure surge in the engine cylinder $(\mathrm{dp} / \mathrm{d} \alpha)$. Similarly, as in the adopted method of determination of $\alpha_{\mathrm{pw}}$, also determination of the start of fuel self-ignition $\left(\alpha_{\mathrm{psp}}\right)$ based on the indicator diagram involves a certain simplification because it does not take into account all phenomena and reactions taking place in the process of actual self-ignition of the fuel.

Literature on this topic contains examples of determination of the start of self-ignition of fuel in the engine cylinder based on the heat release speed (the first zero value of $\delta \mathrm{Q} / \mathrm{d} \alpha$ ). However, one must keep in mind that the values of $\delta \mathrm{Q} / \mathrm{d} \alpha$ are calculated based on very different computational models. Therefore, the start of self-ignition determined using this method, depending on the thermodynamic model, can differ by as much as $15 \%$. Consequently, in this publication the start of fuel self-ignition $\left(\alpha_{\mathrm{psp}}\right)$ was determined based on the changes of $\mathrm{dp} / \mathrm{d} \alpha$ as a function of the angle of the crankshaft, which for the tested fuels and the 3 engine loads is shown in Fig. 2. The data shown in Fig. 2 leads to several important observations concerning the start of selfignition $\left(\alpha_{\mathrm{psp}}\right)$ of the fuels that were tested:
- at low engine loads, only the TM/135/18 fuel has a selfignition start value different than the other fuels. The earlier self-ignition of that fuel is correlated with a lower concentration of $\mathrm{NO}_{\mathrm{x}}$ in the exhaust gas compared to the TM/134/18 fuel. At this engine load, the $\mathrm{TM} / 135 / 18$, as the only one of the fuels with special additives that were tested, makes it possible to reduce the $\mathrm{NO}_{\mathrm{x}}$ concentration compared to the reference fuel; at the load of $100 \mathrm{Nm}$, the difference is as large as 5\%;

- at medium engine loads the differences in the values of $\alpha_{\mathrm{psp}}$ are not very large, but one can notice that, similar to the concentration of nitrogen oxides in the exhaust gas, the values of $\alpha_{\mathrm{psp}}$ are monotonously decreasing for the successive fuels (TM/134/18, TM/135/18, TM/136/18, $\mathrm{TM} / 154 / 18$ ), which indicates an earlier start of selfignition;

- at high engine loads, all fuels with a special additive package (at different concentrations) are characterized, also monotonously, by an ever earlier start of selfignition; however, the changes of $\alpha_{\text {psp }}$ are much larger than at medium engine loads. This is probably due to the aforementioned stronger action of one of the additives at the higher temperatures in the cylinder of an engine working under a higher load. This results in a reduction of the $\mathrm{NO}_{\mathrm{x}}$ concentration in the exhaust gas of the engine supplied with the TM/154/18 fuel and working in a higher load range, which is much greater than at medium engine loads, compared to the TM/134/18 fuel.

The impact of the analyzed fuels on the start of fuel self-ignition (in relation to the concentration of nitrogen oxides in the exhaust gas) is important because it has a direct impact on self-ignition delay $\left(\mathrm{t}_{\mathrm{sp}}\right)-$ Fig. 3 .

A comparison of the values of self-ignition delay, tsp, for the three fuels with the content of $10 \%$ of RME with the special additive package (TM/135/18, TM/136/18, $\mathrm{TM} / 154 / 18$ ) with the values of tsp for the reference fuel (TM/134/18) with the value of $7 \%$ of RME, leads to the following conclusion:

- The TM/135/18 fuel is characterized by a much shorter self-ignition delay compared to the TM/134/18 fuel (as much as $23 \%$ ) for a low engine load. Also, when compared to the TM/136/18 and TM/154/18 fuels, at low engine loads, the self-ignition delay is the shortest in the case of the TM/135/18 fuel. This shows an excellent correspondence to the smallest $\mathrm{NO}_{\mathrm{x}}$ concentration in the exhaust gas of the engine working under a low load and supplied with the TM/135/18 fuel, compared to the remaining fuels (Fig. 3). For example, at the engine torque equal to $\mathrm{Mo}=100 \mathrm{Nm}$, the $\mathrm{NO}_{\mathrm{x}}$ concentration in the exhaust gas of an engine burning the TM/135/18 fuel is as much as $5 \%$ smaller than the concentration for the reference fuel (TM/134/18). Unfortunately, at medium and high engine loads, there was no such beneficial impact of the fuel additives in the TM/135/18 fuel on a reduction of the self-ignition delay and the concentration of $\mathrm{NO}_{\mathrm{x}}$ in the exhaust gas, compared to the TM/134/18 fuel. This is important because at high engine loads (when the beneficial impact of the TM/135/18 fuel is negligible), the engine emits the largest quantity of $\mathrm{NO}_{\mathrm{x}}$ and, unfortunately, at this operating range of the engine, 
the EGR exhaust gas recirculation system (which is intended to reduce the concentration of nitrogen oxides in the exhaust gas) is no longer working. Consequently, use of this type of fuel in a diesel engine is not significantly justified.

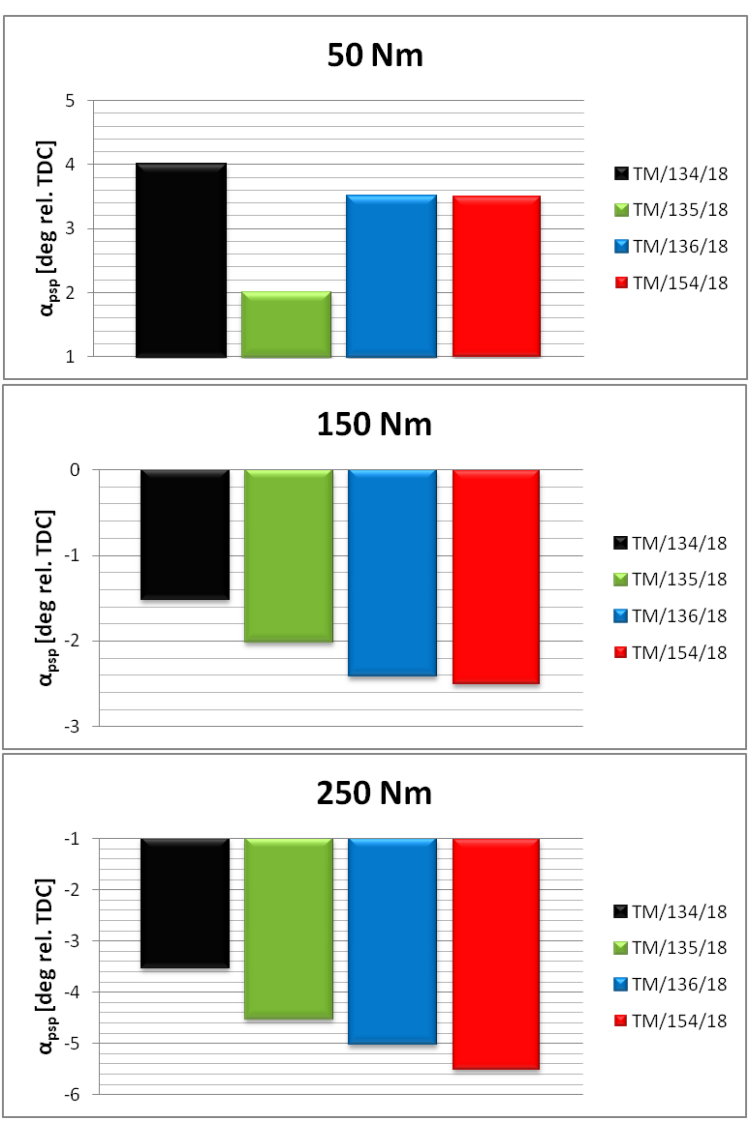

Fig. 2. Start of fuel self-ignition $\left(\alpha_{\mathrm{psp}}\right)$ and $\mathrm{NO}_{\mathrm{x}}$ in the exhaust gas at selected duty points of the engine for the four tested fuels

- The TM/136/18 fuel indicates a completely different nature of changes in the self-ignition delay $\left(\tau_{\mathrm{sp}}\right)$, as a function of engine load, than the TM/135/18 fuel. The data shown in Fig. 3 clearly indicates that, in the entire engine load range, the self-ignition delay is shorter for this fuel that for the reference fuel TM/134/18. What is important is that the beneficial differences between the $\tau_{\mathrm{sp}}$ values for the TM/134/18 fuel and the TM/136/18 fuel increase as the engine loads increases. For the latter fuel, the larger the engine load (higher temperature in the engine cylinder), the greater the reduction of the self-ignition delay compared to the reference fuel (TM/134/18), which corresponds to a greater reduction of $\mathrm{NO}_{\mathrm{x}}$ content in the exhaust gas compared to the TM/134/18 fuel. Consequently, the nature of the changes (reduction of the self-ignition delay) as a function of engine load, between the TM/134/18 fuel and the $\mathrm{TM} / 136 / 18$ fuel, is very correct. However, the quantitative differences in the self-ignition delay values for the $\mathrm{TM} / 134 / 18$ fuel and the TM/136/18 fuel are small $\left(0.5^{\circ}\right.$ crankshaft rotation angle) for a low engine load and $0.9^{\circ}$ crankshaft rotation angle for a medium and high engine load). This translates into minimum differences in $\mathrm{NO}_{\mathrm{x}}$ concentration in the exhaust gas of an engine supplied with the TM/134/18 fuel and the TM/136/18 fuel (1 ppm for a low engine load, 2 ppm for a medium engine load, and $15 \mathrm{ppm}$ for a high engine load). Those differences, especially for the low and medium engine load, are within the measurement error. For this reason, the tests were performed on the TM/154/18 fuel, which contains a two times higher concentration of an additive that reduces the self-ignition delay compared to the TM/136/18 fuel.

- The TM/154/18 fuel, as a function of engine load, leads to the same changes in self-ignition delay compared to the reference fuel (TM/134/18) as the TM/136/18 fuel, which means that at a small engine torque, the reduction of the $\tau_{\mathrm{sp}}$ for the TM/154/18 is smaller (compared to the $\mathrm{TM} / 134 / 18$ fuel) than at a high engine load. Nevertheless, quantitatively, the reduction of the self-ignition delay for the TM/154/18 fuel is almost twice larger than for the TM/136/18 fuel. Consequently, an increase of the concentration of the additive that reduces the selfignition delay in the TM/154/18 fuel has given the expected effect. Consequently, the concentration of $\mathrm{NO}_{\mathrm{x}}$ determined for the fuel in question also decreased, both compared to the TM/136/18 fuel (for a high engine load by approx. 3\%) and, especially, compared to the $\mathrm{TM} / 134 / 18$ fuel (for $\mathrm{Mo}=280 \mathrm{Nm}$, the difference of nitrogen oxides concentration was equal to approx. $7 \%$ ). This is important because such beneficial differences (of $\tau_{\mathrm{sp}}$ and $\mathrm{NO}_{\mathrm{x}}$ ) occur at high engine loads, where the EGR system cannot be used.

The action of the fuel additives that shorten the selfignition delay is very important because in diesel fuels the emission of nitrogen oxides is related most of all to the maximum combustion temperature (and, to a smaller degree, with the availability of oxygen and the duration of the nitrogen oxidation reaction). Consequently, the shorter the self-ignition delay (less time for gathering of the fuel dose in the combustion chamber until self-ignition), the smaller the fuel dose that self-ignites. This results in a less dynamic combustion process (smaller maximum kinematic combustion speed) and, consequently, a lower maximum combustion temperature, which leads to a lower concentration and emission of $\mathrm{NO}_{\mathrm{x}}$ in the exhaust gas. This phenomenon is presented in Fig. 4.

On the other hand, a reduction of the self-ignition delay, tsp, of the fuel leads to a reduction of the time of mixing of fuel with air before the fuel self-ignition, which results in incomplete combustion, which in turn increases the emission of particulate matter and smoke opacity of the exhaust gas. At the same time, a reduction of the $t_{s p}$ shortens the time of gathering of fuel in the combustion chamber before self-ignition, which, as has been mentioned, reduces the maximum and average combustion temperature. A reduction of the combustion temperature leads to combustion of a smaller quantity of soot and PM that have been produced. Consequently, all in all, a reduction of the self-ignition delay of the fuel involves an increased quantity of smoke opacity of the exhaust gas and an increased emission of particulate matter. 

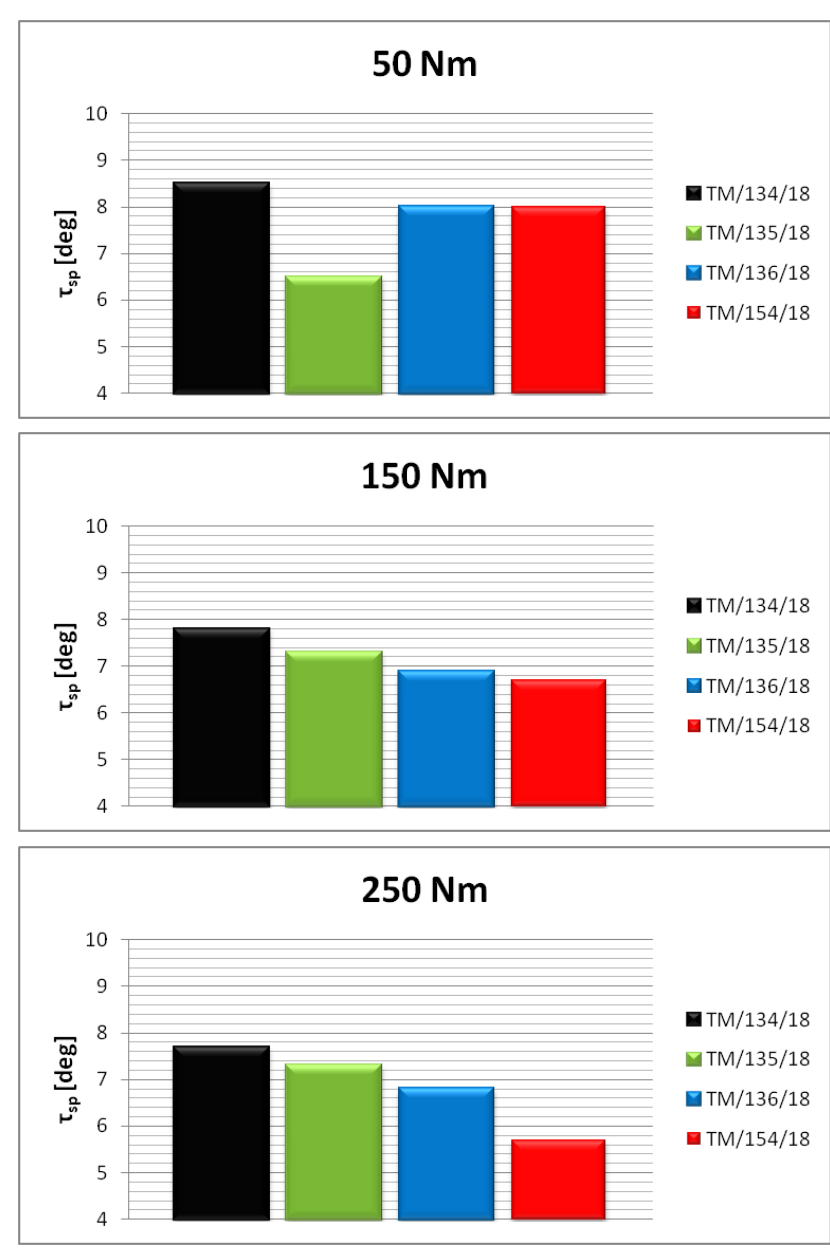

Fig. 3. Fuel self-ignition delay $\left(\mathrm{t}_{\mathrm{sp}}\right)$ and $\mathrm{NO}_{\mathrm{x}}$ in the exhaust gas at selected duty points of the engine for the four tested fuels

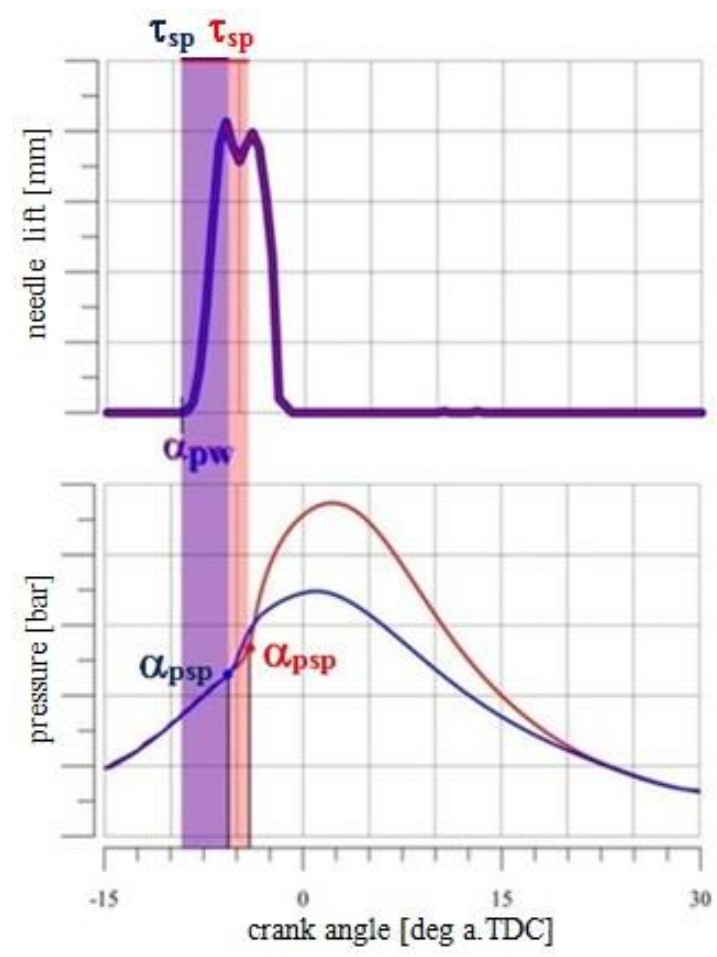

Fig. 4. Changes in the pressure in the engine cylinder as a function of the crank angle for 2 fuels: low LC value (red line), high LC value (blue line)
Usually, a reduced combustion dynamic, which is associated with a shorter self-ignition delay (tsp) results in a smaller maximum combustion pressure. The maximum combustion pressure $\left(\mathrm{p}_{\mathrm{s} . \mathrm{max}}\right)$, shown in Fig. 5, is related, physically, with the maximum combustion temperature, which in turn is the main cause of formation of nitrogen oxides in the engine cylinder. The lowest value of maximum combustion pressure was obtained when the engine was supplied with the TM/154/18 fuel (for each of the engine loads applied), which is greatly correlated with the measured values of concentration of nitrogen oxides in the exhaust gas of the engine.

Of note is the fact that different parameters associated with the engine being supplied with the tested fuels, determined using different measurement methods, lead to the same consistent conclusions. The TM/154/18 fuel, for which the lowest $\mathrm{NO}_{\mathrm{x}}$ concentration was measured in the exhaust gas (especially at a high torque), is also characterized by the earliest start of self-ignition, the shortest fuel self-ignition delay, the smallest rate of pressure increase, and the maximum combustion pressure. A similar conformity was observed when comparing the TM/135/18 fuel to the TM/134/18 fuel and the TM/154/18 fuel to the $\mathrm{TM} / 136 / 18$ fuel. This indicates that there is no randomness in the tests and in their analysis, both with regard to the engine load and, especially, between the tested fuels.

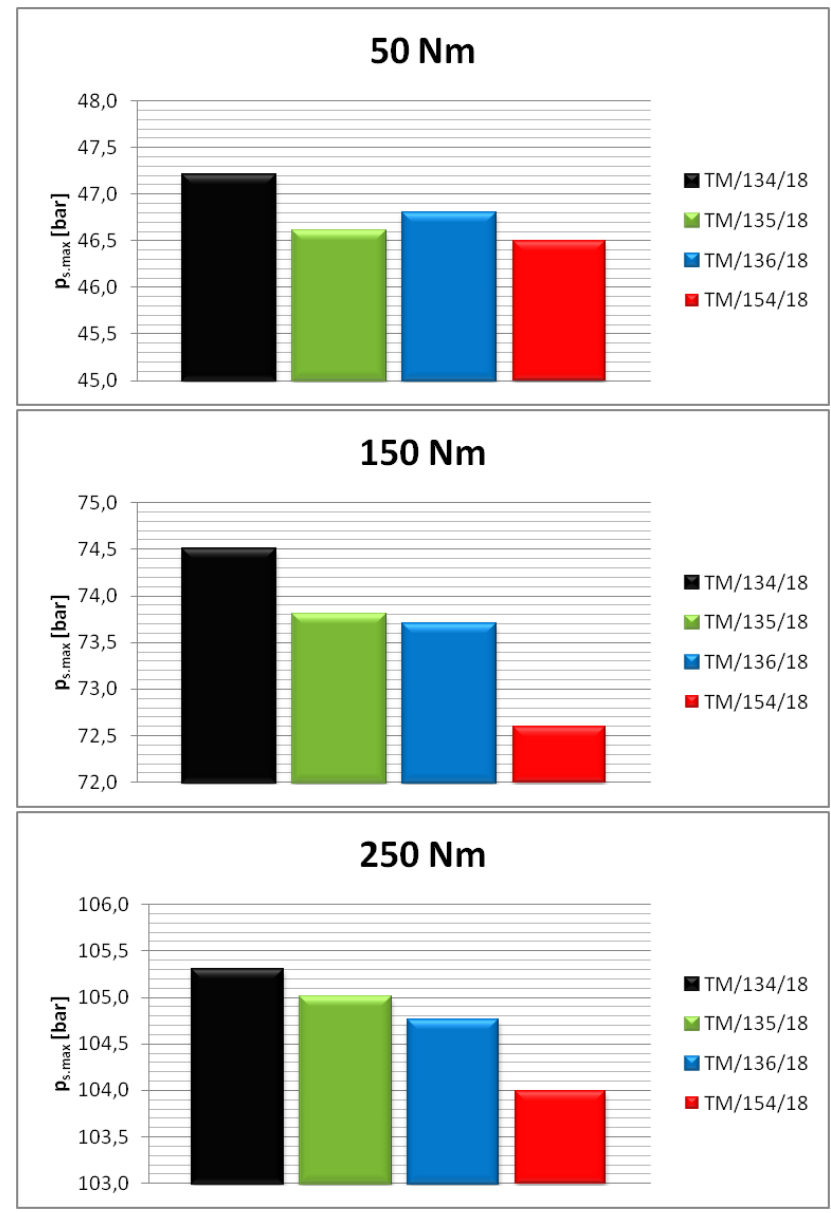

Fig. 5. Maximum combustion pressure $\left(\mathrm{p}_{\mathrm{s} . \max }\right)$ at selected duty points of the engine for the four tested fuels 


\subsection{Parameters of heat release}

In the past, the heat release speed was calculated and analyzed much later than indicator diagrams (when the most important criterion for optimization of combustion engines was no longer general efficiency but rather the composition of the exhaust gas). The heat release speed is most often calculated based on an open indicator diagram, using different thermodynamic computational methods, with the model often used in Europe being integrated in the AVL company software [5].

Because the heat release speed depends, among others, on the crankshaft rotation angle, the engine load, and the type of fuel used, then, line in the case of open indicator diagrams, it is much easier to analyze the commonly defined parameters of those curves than the curve of a function of multiple variables. For the purpose of this paper, the following parameters were used, which were determined based on the $\mathrm{dQ} / \mathrm{d} \alpha$ curve:

- maximum kinetic rate of heat release $\left(\mathrm{dQ}_{\mathrm{k}} / \mathrm{d} \alpha\right)_{\max }$,

- maximum diffusive rate of heat release $\left(\mathrm{dQ}_{\mathrm{d}} / \mathrm{d} \alpha\right)_{\max }$,

- kinematic combustion duration $\left(\alpha_{\text {sp.k }}\right)$,

- diffusive combustion duration $\left(\alpha_{\text {sp.d }}\right)$.

In diesel engines of older generations (with early start of injection and without division of the fuel dose into parts), the maximum kinematic combustion speed $\left(\mathrm{dQ}_{\mathrm{k}} / \mathrm{d} \alpha\right)_{\max }$ was significantly higher than the maximum diffusive combustion speed $\left(\mathrm{dQ}_{\mathrm{d}} / \mathrm{d} \alpha\right)_{\max }$ In such a situation, engines emitted large amounts of both nitrogen oxides and particulate matter. A reduction of the type test limits of $\mathrm{NO}_{\mathrm{x}}$ and $\mathrm{PM}$ emission resulted in design, regulation, and fuel changes (including post-process ones) in modern diesel combustion engines. Those changes involve a reduction of the maximum kinematic speed value (in order to reduce $\mathrm{NO}_{\mathrm{x}}$ emissions) and an increase in the maximum diffusive combustion speed (in order to reduce PM emissions and smoke opacity of exhaust gas).

The brief information presented above and the title of the paper indicate that the impact of the tested fuels on the maximum value of the heat release speed in the kinetic combustion phase $\left(\mathrm{dQ}_{\mathrm{k}} / \mathrm{d} \alpha\right)_{\max }$ is the essence of the tests presented herein. The impact of the three fuels containing a special packet of additives (TM/135/18, TM/136/18, and $\mathrm{TM} / 154 / 18)$, compared to the reference fuel (TM/134/18) on the maximum kinetic combustion speed is presented in Fig. 6. The data indicates that the quantitative changes $\left(\mathrm{dQ}_{\mathrm{k}} / \mathrm{d} \alpha\right)_{\max }$ for the analyzed fuel (for all engine loads) correspond to both the changes in the self-ignition delay $\left(\tau_{\mathrm{sp}}\right)$, the maximum speed of increase of the pressure in the engine cylinder $(\mathrm{dp} / \mathrm{d} \alpha)_{\max }$, the maximum combustion pressure $\left(\mathrm{p}_{\mathrm{s} \text {.max }}\right)$, and of course the concentration of nitrogen oxides $\left(\mathrm{NO}_{\mathrm{x}}\right)$ in the exhaust gas.

One must keep in mind that such parameters as e.g. hourly fuel consumption $\left(\mathrm{G}_{\mathrm{pal}}\right)$, the exhaust gas temperature $\left(\mathrm{t}_{\mathrm{sp}}\right)$, and the charging pressure $\left(\mathrm{p}_{\mathrm{d}}\right)$ are the results of measurements associated with completion of a large number of engine operating cycles (and are averaged for all cylinders of the engine). On the other hand, indicator diagrams and heat release speed diagrams apply to a specific individual operating cycle of the engine (and one cylinder of the engine). Because, as has been found, the maximum kinetic combustion speed $\left(\mathrm{dQ}_{\mathrm{k}} / \mathrm{d} \alpha\right)_{\max }$ is the lowest among all the tested fuels, for medium and high engine loads (which are the most important from the operational point of view) for the TM/154.18 fuel, then in combination with the smallest values of $t_{s p}$ and, most of all, the lowest value of $\mathrm{NO}_{\mathrm{x}}$ concentration in the exhaust gas, this fuel is certainly preferable for use in diesel engines.

Because successive operating cycles of a piston combustion engine are clearly subject to natural fluctuation, then during an analysis of the fast-changing phenomena taking place in the engine cylinder, one cannot afford to analyze a randomly selected engine operating cycle. Therefore, in the tests that were performed - in the measurements and analyses of the open indicator diagrams and in the heat release speed calculated based on those diagrams for each engine duty point, a representative indicator diagram was determined which (in accordance with the research method most commonly used in the world) is the result of averaging of a hundred successive engine operating cycles. Consequently, it is possible to correlate parameters measured in many engine operating cycles (e.g. $G_{p a l}, t_{s p}, p_{d}$ ) with the parameters of representative indicator diagrams and head release speed diagrams. This is another confirmation of the fact that the analyzed differences in the values of the parameters for the tested fuels are not random but rather result directly from the quality and quantity of the fuel additives used in the packages (TM/135/18, TM/136/18, and TM/154/18).

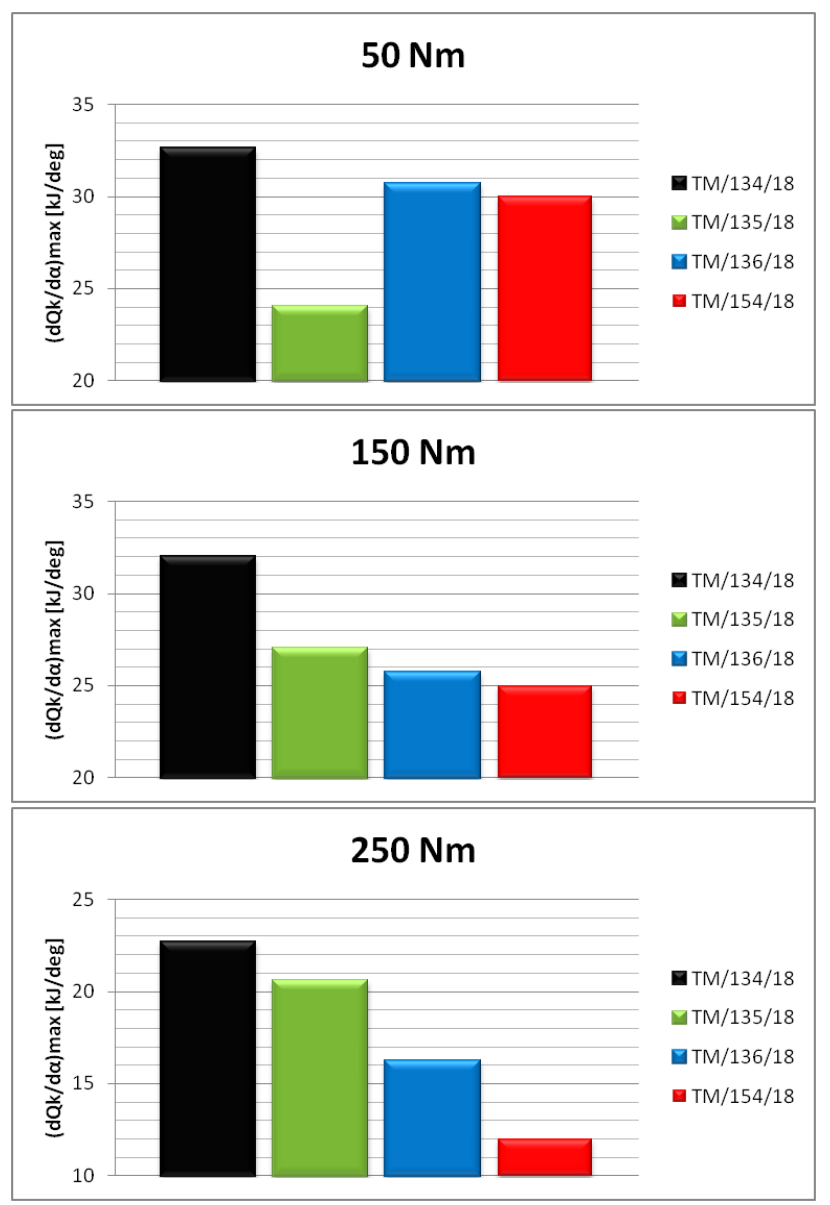

Fig. 6. Maximum heat release speed $\left(\mathrm{dQ}_{\mathrm{k}} / \mathrm{d} \alpha\right)_{\max }$ in the engine cylinder in the kinetic combustion phase at selected engine duty point for the four tested fuels 
Only the TM/135/18 fuel (compared to the TM/134/18 fuel) is characterized by a reduced maximum kinetic combustion speed $(26.4 \%)$ at low engine load. This is accompanied by a significant reduction of the self-ignition delay $(23.5 \%)$ and, consequently, a reduction of the concentration of nitrogen oxides in the exhaust gas.

After the kinetic combustion phase (immediately after the self-ignition of the fuel), the diffusive combustion phase takes place. The speed of diffusive combustion is associated in practice with the speed of the fuel injected into the engine cylinder (because this stage of fuel combustion occurs constantly at a high excess of air and involves a fuel-air mixture that is preliminarily mixed in the combustion chamber in the self-ignition delay period). Therefore, by controlling (increasing) the speed of fuel injection in this combustion stage, it is possible to influence the maximum diffusive combustion speed $\left(\mathrm{dQ}_{\mathrm{d}} / \mathrm{d} \alpha\right)_{\max }$. This is important because an increase in the diffusive combustion speed usually leads to combustion of a part of soot that has been produced, which constitutes a significant part of the weight of the particulate matter (PM) and consequently reduces the overall PM emission and the smoke opacity of the exhaust gas. The maximum value of the heat release speed in the diffusive combustion phase $\left(\mathrm{dQ}_{\mathrm{d}} / \mathrm{d} \alpha\right)_{\max }$ for 3 engine loads and the tested fuels is shown in Fig. 7.

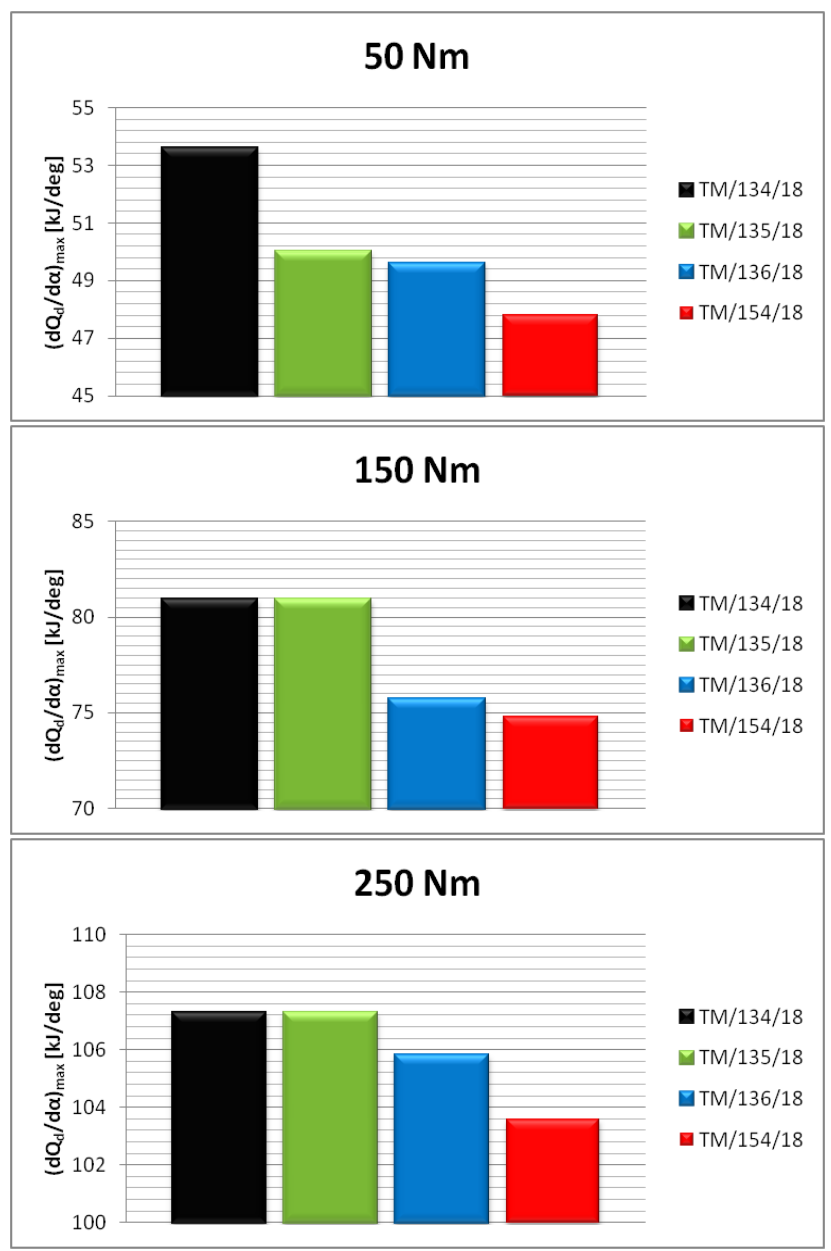

Fig. 7. Maximum heat release speed $\left(\mathrm{dQ}_{\mathrm{d}} / \mathrm{d} \alpha\right)_{\max }$ in the engine cylinder in the diffusive combustion phase at selected engine duty point for the four tested fuels
The data indicates that in the case of the TM/135/18 fuel the maximum diffusive combustion speed $\left(\mathrm{dQ}_{\mathrm{d}} / \mathrm{d} \alpha\right)_{\max }$ decreased only at low engine loads compared to the TM/134/18 fuel and that the former fuel had no impact (compared to the reference fuel) on the $\left(\mathrm{dQ}_{\mathrm{d}} / \mathrm{d} \alpha\right)_{\max }$ at higher engine loads (medium and high). This involves a small (for a low engine load) reduction of the smoke opacity of the exhaust gas. This demonstrates that the additive used in this fuel (TM/135/18) has the greatest impact at this engine load and at the low temperature in the cylinder. This was not observed in the case of the TM/136/18 and TM/154/18 fuels.

Contrary to frequent preliminary analyses, a decrease of the maximum diffusive combustion speed $\left(\mathrm{dQ}_{\mathrm{d}} / \mathrm{d} \alpha\right)_{\max }$ does not have to be accompanied by an increase in the smoke opacity of the exhaust gas. This is the case here: at a low load of the engine supplied with the TM/135/18 fuel there was a small decrease of $\left(\mathrm{dQ}_{\mathrm{d}} / \mathrm{d} \alpha\right)_{\max }$ and, simultaneously, a reduction of smoke opacity of the exhaust gas (compared to the TM/134/18 fuel). This is possible because the reduction of the smoke opacity of the exhaust gas (D) is associated not only with the maximum value of the diffusive combustion speed but also with the duration of this combustion phase, which is often forgotten in basic analyses of the mechanism of formation of soot, which is the key cause of smoke opacity and emission of PM in exhaust gas.

However, one must keep in mind that although an increase in the value of $\left(\mathrm{dQ}_{\mathrm{d}} / \mathrm{d} \alpha\right)_{\max }$ (e.g. by using fuel additives) is a good way to reduce PM emissions in engine exhaust gas, elongation of the combustion process in this phase, which does not bring the same effect, involves a harmful elongation of the entire combustion process and a harmful (from the standpoint of overall efficiency of the engine) shift of the end of combustion to a later moment - see the diagram in Fig. 8.

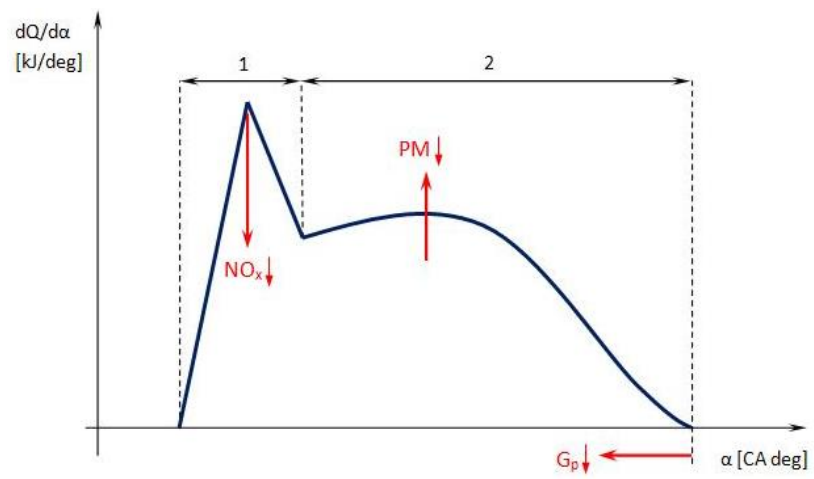

Fig. 8. Changes in the heat release speed in a diesel engine cylinder: $1-$ kinetic combustion speed phase, 2 - diffusive combustion speed phase

Therefore, fuel additives should increase the combustion speed in the diffusive phase rather than extending the duration of this combustion stage. The values of the parameter defining the duration of diffusive combustion $\left(\alpha_{\text {sp.d }}\right)$ are shown in Fig. 9.

The duration of diffusive combustion of the TM/135/18 fuel at low and medium engine loads is longer than the duration for the TM/134/18 fuel. Consequently, at a slightly lower maximum heat release speed in the diffusive combus- 
tion phase, the much longer duration results in combustion of a larger quantity of soot that has been produced and, consequently, in a reduced smoke opacity and, most likely, a reduced emission of particulate matter in the engine exhaust gas. In the case of the TM/136/18 and TM/154/18 fuels, which have twice as high concentrations of the additive that shortens the self-ignition delay as the TM/135/18 fuel, the qualitative impact on reduction of the $\left(\mathrm{dQ}_{\mathrm{d}} / \mathrm{d} \alpha\right)_{\max }$ (Fig. 9) is the same. However an increase of the additive that increases the value of LC in the TM/154/18 fuel (compared to the TM/136/18 fuel) resulted in both a decrease of the value of $\left(\mathrm{dQ}_{\mathrm{k}} / \mathrm{d} \alpha\right)_{\max }$ (thanks to the shortening of the self-ignition delay $\mathrm{t}_{\mathrm{sp}}$ ) and, unfortunately, a decrease of the maximum diffusive combustion speed $\left(\mathrm{dQ}_{\mathrm{d}} / \mathrm{d} \alpha\right)_{\max }$. This worsened the conditions for combustion of the soot that had been produced, which resulted in a higher smoke opacity of the exhaust gas at medium and high engine loads for the $\mathrm{TM} / 136 / 18$ and TM/154/18 fuels.

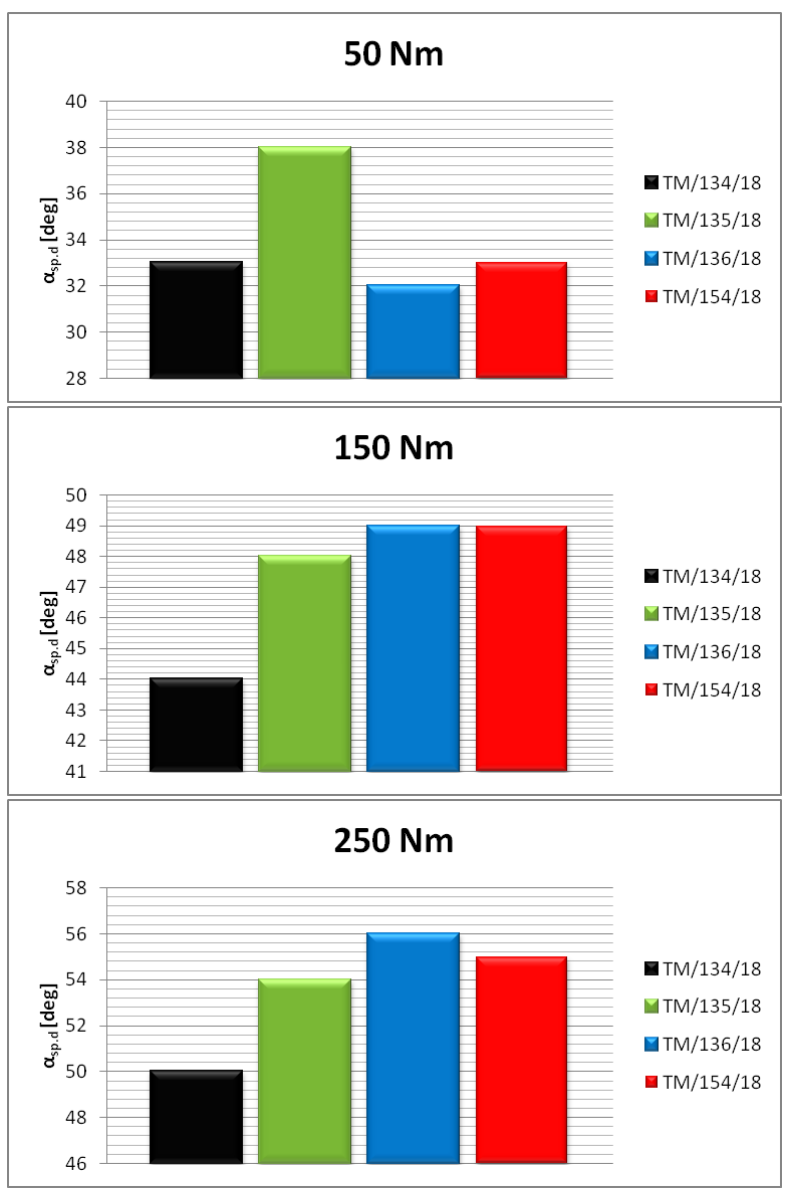

Fig. 9. Duration of diffusive combustion $\left(\alpha_{\text {sp.d }}\right)$ in the cylinder at selected duty points of the engine for the four tested fuels

In the case of the TM/136/18 fuel and the TM/154/18 fuel, the process of combustion in the diffusive phase was a little longer (compared to the TM/134/18 fuel), but this did not result in a reduced smoke opacity of the exhaust gas compared to the latter fuel, because, unfortunately, of the dominant phenomenon of reduced maximum diffusive combustion speed $\left(\mathrm{dQ}_{\mathrm{d}} / \mathrm{d} \alpha\right)_{\max }$. On the other hand, the slightly longer combustion process in the diffusive phase for the two fuels containing a package of additives can be linked to a small increase of the hourly fuel consumption (approx. 1\%) compared to the reference fuel.

The above discussion indicates that when analyzing the changes of the diffusive heat release speed in the engine cylinder one must not use only the maximum value of that parameter (e.g. when analyzing the smoke opacity of the exhaust gas and the particulate matter emission) and, instead, one should also include the duration of the process. This is important because the duration of diffusive combustion (in piston combustion engines) is many times longer than the duration of kinetic combustion $\left(\alpha_{\text {sp.k }}\right)-$ Fig. 10. In the case of the TM/135/18 fuel, which is the most effective with regard to the $\mathrm{NO}_{\mathrm{x}}$ concentration in the exhaust gas at low engine loads, thanks to the biggest reduction of the self-ignition delay and to the reduction of the maximum kinetic combustion speed, the duration of combustion in this phase does not significantly change compared to the TM/134/18 fuel. This leads to the conclusion that reduction of $\mathrm{NO}_{\mathrm{x}}$ concentration in the exhaust gas, especially at low engine loads, is influenced only by the reduction of $\left(\mathrm{dQ}_{\mathrm{k}} / \mathrm{d} \alpha\right)_{\max }$. The situation is different in the case of the TM/136/18 fuel and, in particular, the TM/154/18 fuel, for which a reduction of nitrogen oxides concentration in the exhaust gas is accompanied, at medium and high engine load, by a great reduction of self-ignition delay $\left(\mathrm{t}_{\mathrm{sp}}\right)$, a reduction of the maximum heat release speed in the kinetic combustion phase $\left(\mathrm{dQ}_{\mathrm{k}} / \mathrm{d} \alpha\right)_{\max }$, and, at the same time, a reduction in the duration of combustion in the kinetic phase $\left(\alpha_{\text {sp.k }}\right)$.

Based on the results of the tests presented herein, one must conclude that when analyzing the heat release speed in the engine cylinder one must not focus only on the maximum value of kinetic combustion speed (compared, e.g. to the $\mathrm{NO}_{\mathrm{x}}$ concentration in the exhaust gas) and on the maximum value of diffusive combustion speed (compared to the PM emission and the smoke opacity of the exhaust gas); instead, one should also consider the duration of combustion in the kinetic phase and the diffusive phase. Proper consideration of the value of all those parameters enables full understanding of the mechanisms of the fast-changing processes taking place in the cylinder of a piston combustion engine. One must also keep in mind that an extension of the diffusive combustion part works in two ways: on the one hand, it reduces the smoke opacity and the emission of particulate matter in the exhaust gas and, on the other hand, it increases the energy losses (which should be used to increase the internal energy of the operating medium and to perform technical work) associated with evacuation of the exhaust gas. Consequently, changes in the design, regulation, and fuel parameters in order to decrease $\mathrm{NO}_{\mathrm{x}}$ and $\mathrm{PM}$ emissions should be based, most of all, on a reduction of the maximum value of the kinetic combustion speed and an increase of the maximum diffusive combustion speed, instead of on a change of the duration of those stages of the combustion process.

\section{Conclusions}

The tests that were performed made it possible to draw the following major conclusions concerning a comparison of the impact of the tested fuels (TM/135/18, TM/136/18, 
and TM/154/18) with cetane-detergent additives in diesel fuel with RME content increased to $10 \%$, compared to the reference fuel with $8 \% \mathrm{RME}(\mathrm{TM} / 134 / 18)$ :

1. The TM/135/18 fuel has an impact on the engine operation process basically only at low engine loads. At such loads, a shorter self-ignition delay and a lower maximum kinetic speed $\left(\mathrm{dQ}_{\mathrm{k}} / \mathrm{d} \alpha\right)_{\max }$ were observed, associated with a small decrease of $\mathrm{NO}_{\mathrm{x}}$ emissions in the exhaust gas. Also, at low engine loads, the maximum diffusive combustion speed $\left(\mathrm{dQ}_{\mathrm{d}} / \mathrm{d} \alpha\right)_{\max }$ slightly decreased for this fuel. This resulted in a small (in principle within the measurement error) reduction of the smoke opacity of the exhaust gas.

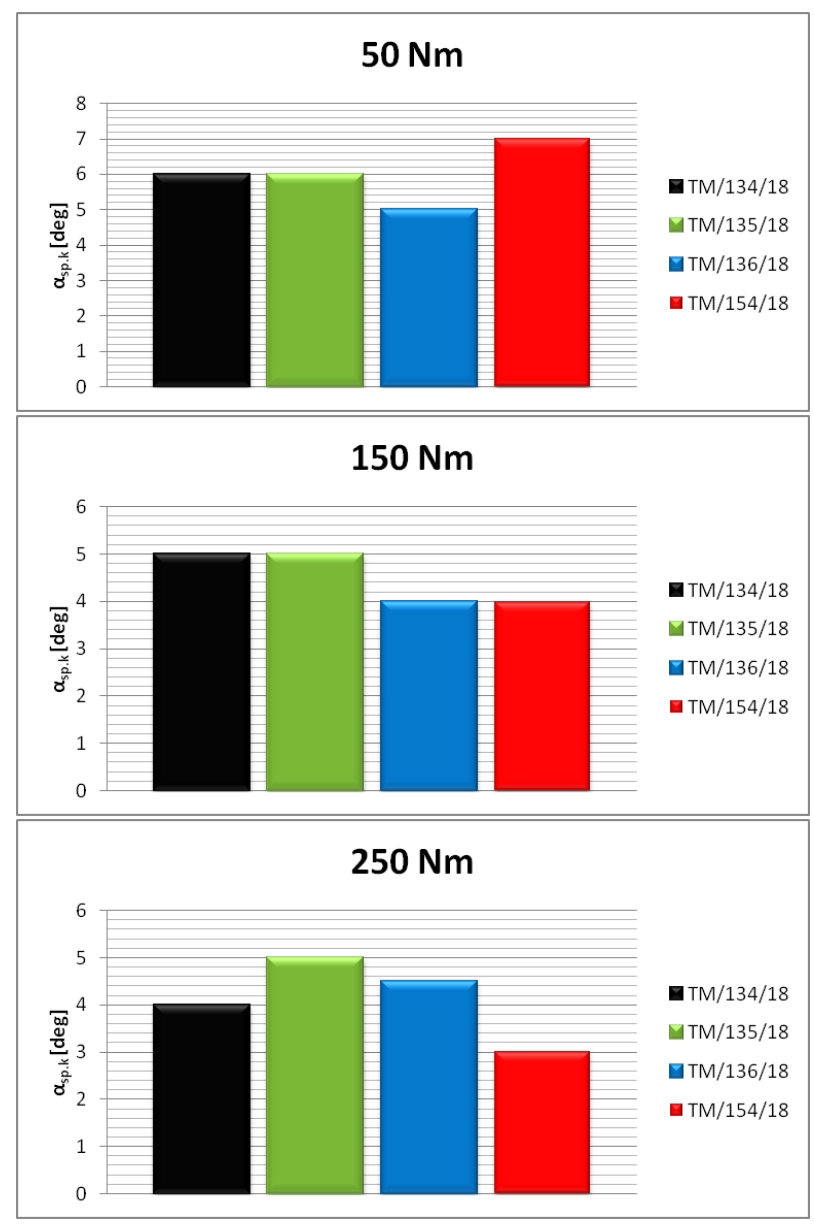

Fig. 10. Duration of kinetic combustion $\left(\alpha_{\text {sp.k }}\right)$ in the cylinder at selected duty points of the engine for the four tested fuels

2. The TM/136/18 fuel has a different qualitative action compared to the TM/135/18 fuel because its impact on the operating process of the engine is noticeable only at medium and high engine loads. At such loads, in the case of the $\mathrm{TM} / 136 / 18$ fuel, the fuel self-ignition delay $\left(\mathrm{t}_{\mathrm{sp}}\right)$, the maximum kinetic combustion speed $\left(\mathrm{dQ}_{\mathrm{k}} / \mathrm{d} \alpha\right)_{\max }$, and the $\mathrm{NO}_{\mathrm{x}}$ concentration in the exhaust gas decreased. However, because usually a decrease of the maximum kinetic combustion speed accompanies a reduction of the maximum diffusive combustion speed (a reduction of the average combustion speed), also in this case, for the TM/136/18 fuel, the maximum diffusive combustion speed $\left(\mathrm{dQ}_{\mathrm{d}} / \mathrm{d} \alpha\right)_{\max }$ was slightly lower, which unfortunately resulted in a higher smoke opacity of the exhaust gas. As a result of the rela- tively small change of the impact of the TM/136/18 fuel on the reduction of the self-ignition delay $\left(t_{\mathrm{sp}}\right)$ and on the reduction of the maximum kinetic combustion speed $\left(\mathrm{dQ}_{\mathrm{k}} / \mathrm{d} \alpha\right)_{\max }$ and, consequently, on the small practical reduction of nitrogen oxide $\left(\mathrm{NO}_{\mathrm{x}}\right)$ concentration in the exhaust gas, the decision was to use the TM/154/18 fuel in which the concentration of the additive that shortens the $t_{s p}$ is twice as high as in the TM/136/18 fuel.

3 . The TM/154/18 fuel is characterized by similar qualitative changes of the analyzed operating parameters of the engine as the TM/136/18 fuel, whereby the changes are much greater at medium and high engine loads. The impact of the TM/154/18 fuel, compared to the TM/134/18 fuel, for the lowest engine loads $(0-80 \mathrm{Nm})$, with reference to a majority of the parameters that are important from the point of view of the energy characteristics and the composition of the engine exhaust gas, is negative. Only at higher loads (up to the maximum load), a beneficial effect was observed of the additives in the TM/154/18 fuel (whose quantity was larger than in the TM/134/18 fuel) on a significant reduction of the maximum kinetic combustion speed (by a significant reduction of the self-ignition delay) and a reduction of $\mathrm{NO}_{\mathrm{x}}$ concentration in the engine exhaust gas (compared to the TM/134/18 fuel). Unfortunately, in such conditions, the maximum diffusive combustion speed is also reduced, which leads to an increase in smoke opacity of the engine exhaust gas at these load values (medium and high). This is a typical phenomenon associated with an attempt to control the fast-changing heat release speed in the engine cylinder: a reduction of $\left(\mathrm{dQ}_{\mathrm{k}} / \mathrm{d} \alpha\right)_{\max }$ in order to reduce the emission of $\mathrm{NO}_{\mathrm{x}}$ in the exhaust gas most often leads to a reduction of the average combustion speed, which also involves a reduction of the maximum diffusive combustion speed, which in turns increases the smoke opacity of the exhaust gas.

4. The use of the additive in the TM/136/18 fuel made it possible to determine the appropriate direction of quantitative changes in relation to the value of the energy characteristics and the composition of the exhaust gas (compared to the TM/134/18 fuel). However, the changes in the values of those characteristics were not satisfactory from the practical point of view becouse they resulted from insufficient chonges in the values of the parameters that determine the physico-chemical phenomena that caused them (selfignition delay and maximum kinetic combustion speed). This is why further tests were performed on the TM/154/18 fuel, which differed from the TM/136/18 fuel only by the greater content of the additive that reduced the self-ignition delay $\left(\mathrm{t}_{\mathrm{sp}}\right)$. Compared to the TM/154/18 fuel, it must be concluded that the reduction of nitrogen oxides $\left(\mathrm{NO}_{\mathrm{x}}\right)$ in the exhaust gas by over $3 \%$ for the load of $250 \mathrm{Nm}$ and $7 \%$ for the maximum engine load, which was associated with the shorter self-ignition delay (by over 30\%) and the reduction of the maximum kinetic combustion speed $\left(\mathrm{dQ}_{\mathrm{k}} / \mathrm{d} \alpha\right)_{\max }$ compared to the reference fuel (TM/134/18) brought the expected results. Thus, it must be confirmed that only the TM/154/18 fuel has a practical beneficial effect on the significant operating parameters of the engine.

\section{Acknowledgements}

This Project was supported INNOCHEM/ POIR 01.02.00-000028/17. 


\section{Nomenclature}

$\begin{array}{llll}\alpha_{\mathrm{pw}} & \text { start of injection } & \mathrm{dQ} / \mathrm{d} \alpha & \text { diffusion rate of heat release } \\ \alpha_{\mathrm{psp}} & \text { start of self-combustion } & \tau_{\mathrm{s}} & \text { delay of self-combustion } \\ \alpha_{\mathrm{sp} . \mathrm{d}} & \text { time of diffusion combustion } & \mathrm{CI} & \text { compression ignition } \\ \alpha_{\mathrm{sp} . \mathrm{k}} & \text { time of kinetic combustion } & \mathrm{p}_{\mathrm{s} . \mathrm{max}} & \text { max combustion pressure } \\ \mathrm{dQ} / \mathrm{d} \alpha & \text { kinetic rate of heat release } & \mathrm{RME} & \text { rapeseed methyl ester }\end{array}$

\section{Bibliography}

[1] SIEMIONOW, N. Chemical kinetics and chain reactions. Oxford University Press. 1935.

[2] CURRAN, H.J. et al. A comprehensive modelling study of n-heptane oxidation. Combustion and Flame. 1998, 114, 149-177.

[3] ZEDOR, J., TAATJES, C.A. et al. Kinetics of elementary reactions in low-temperature autoignition chemistry. Progress in Energy and Combustion Science. 2011, 37(4), 371421.

Winicjusz Stanik, DSc. - Oil and Gas Institute National Research Institute, Cracow.

e-mail: winicjusz.stanik@inig.pl
[4] OHTA, Y., FURUTANI, M. Identification of cool and blue flames in compression ignition. Archivum Combustionis. 1991, 11(1-2).

[5] STANIK, W. Wpływ dodatku zwiększającego liczbę cetanową na właściwości zapłonowe i proces spalania oleju napędowego w silniku o zapłonie samoczynnym. Nafta-Gaz. 2019, 9, 651-659.

Jerzy Cisek, DSc., DEng. - Faculty of Mechanical Engineering, Cracow University of Technology.

e-mail: jcisek@pk.edu.pl 